University of New Orleans

ScholarWorks@UNO

3-2009

\title{
Exercise-and Hypoxia-Induced Anaerobic Metabolism and Recovery: A Student Laboratory Exercise Using Teleost Fish
}

Bernard Rees

University of New Orleans, brees@uno.edu

Follow this and additional works at: https://scholarworks.uno.edu/biosciences_facpubs

Part of the Biology Commons

\section{Recommended Citation}

Rees, B.B., Boily, P. and Williamson, L.A. 2009. Exercise-and hypoxia-induced anaerobic metabolism and recovery: a student laboratory exercise using teleost fish. Advances in Physiology Education 33 (1): $72-77$.

This Article is brought to you for free and open access by the Department of Biological Sciences at ScholarWorks@UNO. It has been accepted for inclusion in Biological Sciences Faculty Publications by an authorized administrator of ScholarWorks@UNO. For more information, please contact scholarworks@uno.edu. 


\section{Exercise- and hypoxia-induced anaerobic metabolism and recovery: a student laboratory exercise using teleost fish}

B. B. Rees, P. Boily and L. A. C. Williamson Advan in Physiol Edu 33:72-77, 2009. ;

doi: 10.1152/advan.90188.2008

You might find this additional info useful...

This article cites 16 articles, 7 of which you can access for free at: http://advan.physiology.org/content/33/1/72.full\#ref-list-1

This article has been cited by 1 other HighWire-hosted articles: http://advan.physiology.org/content/33/1/72\#cited-by

Updated information and services including high resolution figures, can be found at: http://advan.physiology.org/content/33/1/72.full

Additional material and information about Advances in Physiology Education can be found at: http://www.the-aps.org/publications/ajpadvan

This information is current as of August 8, 2012. 


\title{
Exercise- and hypoxia-induced anaerobic metabolism and recovery: a student laboratory exercise using teleost fish
}

\author{
B. B. Rees, ${ }^{1}$ P. Boily, ${ }^{1,2}$ and L. A. C. Williamson ${ }^{1}$ \\ ${ }^{1}$ Department of Biological Sciences, University of New Orleans, New Orleans, Louisiana; and ${ }^{2}$ Department of Biology \\ and Environmental Sciences, Western Connecticut State University, Danbury, Connecticut
}

Submitted 9 September 2008; accepted in final form 20 January 2009

\begin{abstract}
Rees BB, Boily P, Williamson LAC. Exercise- and hypoxiainduced anaerobic metabolism and recovery: a student laboratory exercise using teleost fish. Adv Physiol Educ 33: 72-77, 2009; doi:10.1152/advan.90188.2008.-Anaerobic metabolism is recruited in vertebrates under conditions of intense exercise or lowered environmental oxygen availability (hypoxia), typically resulting in the accumulation of lactate in blood and tissues. Lactate will be cleared over time after the reoxygenation of tissues, eventually returning to control levels. Here, we present a laboratory exercise developed as part of an upper-level vertebrate physiology class that demonstrates the effects of exercise and hypoxia exposure on blood lactate in fish and the subsequent decrease in lactate during recovery. Typically, the results obtained by students demonstrate that both treatments cause significant increases in blood lactate concentrations (two to three times higher than control values) that decrease back to normal values within $3 \mathrm{~h}$ of recovery under normoxia. The procedures described are generally applicable to other fish species and provide an alternative to using humans or other mammalian species to investigate anaerobic metabolism.
\end{abstract}

lactic acid; oxygen

MOST ANIMALS generally rely on aerobic metabolism for the bulk of their energy production because of the high yield of ATP, the wide range of oxidizable substrates, and the relatively benign end products compared with anaerobic metabolism. However, anaerobic metabolism will be used if the rate of oxygen delivery to tissues is insufficient for aerobic ATP production, e.g., during intense exercise or when environmental oxygen is low (hypoxia) or absent (anoxia) $(8,15)$. The end product of anaerobic metabolism of carbohydrate in most vertebrates is lactate, although fish of the genus Carassius can produce ethanol during hypoxia $(8,14,19)$. Some of this lactate leaves the tissues where it was produced and appears in the blood stream. When oxygen delivery is restored, lactate is converted back into pyruvate and either oxidized to $\mathrm{CO}_{2}$ and $\mathrm{H}_{2} \mathrm{O}$ or incorporated into glycogen, causing blood lactate to decrease. Therefore, the blood lactate concentration is routinely used as an indicator of the extent of anaerobic metabolism and to assess the speed of recovery after a period of anaerobic metabolism $(15,20)$.

Animal and human physiology courses typically discuss the role of anaerobic glycolysis during periods of intense exercise or hypoxia exposure. Most published laboratory experiments aimed at investigating this physiological process are either designed to use human subjects (17) or are limited to the effects of exercise with little, if any, discussion of the effects of

Address for reprint requests and other correspondence: P. Boily, Dept. of Biology and Environmental Sciences, Western Connecticut State Univ., 181 White St., Danbury, CT 06810 (e-mail: boilyp@wcsu.edu). hypoxia exposure $(4,11)$. Although the use of human subjects and the focus on the effects of exercise is preferred and justified under some pedagogical contexts (e.g., courses specifically dedicated to human exercise physiology), courses designed to cover a broader range of organisms and environmental stresses can benefit from having students perform experiments investigating the effects of hypoxia (in addition or as an alternative to exercise) on anaerobic metabolism and recovery in nonmammalian vertebrates or invertebrates. The use of "lower organisms" as experimental subjects has the additional practical advantage of meeting safety, ethical, and legal concerns that favor the use of the least sentient species that can provide satisfactory results (10).

Here, we describe a laboratory exercise that we developed as part of an upper-level vertebrate physiology course that supports and complements lecture material on anaerobic metabolism. Typically, lectures describe the three ATP production mechanisms (direct phosphorylation, anaerobic metabolism, and aerobic metabolism) and their associated physiological advantages and disadvantages as well as the conditions that can induce an increase in the use of anaerobic metabolism in animals (exercise and environmental hypoxia). Similar to another laboratory exercise that we recently described (1), the objective of the laboratory is not only to reenforce lectures but also to train students in a wide range of laboratory and analytical skills. The specific goal of the laboratory exercise is for student to address the following questions: 1) Do intense exercise and hypoxia exposure induce anaerobic metabolism in fish? and 2) How long does it take these fish to recover from these treatments? Both of these questions are addressed by comparing whole blood lactate concentrations of fish exposed to control conditions with fish that are exercised to exhaustion or exposed to hypoxia and with fish exposed to control conditions for various time periods after being exercised or exposed to hypoxia.

\section{MATERIALS AND METHODS}

Students work in groups of two or three, analyze data collected by all groups from all laboratory sections, and write reports based on these results. The exercise requires two 3-h laboratory sessions for each type of experiment (exercise or hypoxia exposure); we alternate the type of experiment used in fall and spring semesters.

\section{Equipment}

The following pieces of equipment are necessary or highly recommended:

- Spectrophotometers (1 per group)

- Vortex mixers (1 per group)

- Adjustable pipettors (one 200- $\mu$ l capacity and one $1,000-\mu 1$ capacity per group) 
- Repeating pipettor capable of dispensing volumes of 50-500 $\mu \mathrm{l}$ (1 per group). Although not essential, repeating pipettors substantially minimize mistakes made by students when dispensing identical volumes of a given solution in multiple tubes

- Microcentrifuge (1 for the class)

- Analytical balances (0.1-mg accuracy; 1-3 for the class)

- Top-loading balances (0.01-g accuracy; $1-3$ for the class)

- Aquaria with aeration and filtration equipment (3 or 4 for the class)

- Compressed $\mathrm{N}_{2}$ cylinder and regulator (1 of each for the class; required for the hypoxia experiment only)

- Dissolved $\mathrm{O}_{2}$ meter ( 1 for the class; required for the hypoxia experiment only)

- $37^{\circ} \mathrm{C}$ water bath to incubate samples (1 for the class)

- Computers with statistical and graphing software (at least 3 for the class)

\section{Disposable Supplies}

Disposable supplies include the following:

- Microcentrifuge tubes

- Microcapillary tubes

- Pipet tips

- Razor blades

- Spectrophotometer cuvettes

- Solutions (see the APPENDIX)

- Ice buckets

\section{Animals}

The procedures described below were approved by the University of New Orleans Institutional Animal Care and Use Committee. We use a brackish species, the Gulf killifish (Fundulus grandis), which can easily be obtained in bait shops in states along the Gulf of Mexico. The closely related mummichog (Fundulus heteroclitus) can be found in coastal areas of the Atlantic seaboard. Other baitfish or pet store species could potentially be used. Desirable attributes include low cost, reasonable tolerance to exercise or hypoxia, and adequate size. With regard to size, we have found it difficult to sample enough blood from fish $<3-5 \mathrm{~g}$. On the other hand, fish $>10-20 \mathrm{~g}$ require greater cost and space to maintain an appropriate number of individuals. While the great majority of fish produce lactate as the primary end product of anaerobic metabolism, goldfish (Carassius auratus) and other species of the same genus can produce ethanol as well as lactate $(8,14,19)$. Goldfish may be used for this experiment with the caveat that lactate formation is not the sole end product of anaerobic metabolism during either exercise or hypoxia. Typically, we have six groups of two to three students per laboratory section, with two sections per semester. Each student group samples one fish from each of the four treatments, leading to a sample size of 48 fish (12 fish for each of the four treatments: control, exercise or hypoxia, 1-h recovery, and 3-h recovery; see below for details).

In our experiments, Gulf killifish were purchased from a local bait shop and kept in three or four 38-liter aquaria at a density of 10-20 fish/aquarium (depending on size) and fed commercial fish food. Water was aerated, filtered, and kept at a salinity (adjusted with Instant Ocean, Aquarium Systems, Mentor, $\mathrm{OH}$ ) similar to that of their habitat $(\sim 9 \mathrm{ppt})$. Fish were typically acclimated for $2 \mathrm{wk}$ to laboratory conditions before the start of the experimental procedures. Feeding was suspended $24 \mathrm{~h}$ before fish were sampled; filtration was continued throughout the experiment.

\section{Experimental Exposures}

Methods for exercise and hypoxia exposure are both described. We typically follow one exposure protocol for all laboratory sections in one semester and alternate exposure protocols in different semesters. Given enough laboratory sections, however, it would be possible to do both exposure types and have enough replication to demonstrate the effects of both treatments in a given semester.

Both exposure protocols employ a control (untreated), a sample taken immediately after the desired exposure (exercise or hypoxia), and two samples taken after increasing durations of recovery (we use 1 and $3 \mathrm{~h}$ ). Because the laboratory period is generally not long enough to provide background information, carry out the exposure, and sample $3 \mathrm{~h}$ later, the 3 -h recovery sample is taken on fish that were subjected to the desired treatment (exercise or hypoxia) 1-2 h before the start of the class period. Ideally, each sample is taken from fish in separate aquaria, but it is possible to double up samples (e.g., immediately after exposure and 1-h recovery) if aquaria or laboratory space is limiting.

\section{Exercise Protocol}

Fish are chased by the laboratory instructor using hands or a net for 5 min or until exhaustion. Chasing is a commonly used method to induce exercise in fish $(6,21)$ and has the advantages of being easy and inexpensive to perform and of allowing multiple individuals to be exercised at once. The chasing protocol is repeated as uniformly as possible in multiple aquaria to provide fish that will be sampled immediately and after 1 and $3 \mathrm{~h}$ of recovery. Although exhaustive exercise can cause delayed mortality in some fish, mainly because of intracellular acidosis (22), we have not experienced any fish mortality, even for individuals that were not killed after being exhausted and that were kept for future experiments.

\section{Hypoxia Protocol}

The concentration of dissolved oxygen (DO) is reduced by gassing one or more aquaria with compressed $\mathrm{N}_{2}$. The target DO is between 0.5 and $1.5 \mathrm{mg} / \mathrm{l}$. This range is below the critical oxygen tension, results in anaerobic metabolism, and is well tolerated by $F$. grandis (20) and F. heteroclitus (2). The sensitivity of other species would have to be obtained from the literature or determined in preliminary experiments. The severity of hypoxia depends on the rate of $\mathrm{N}_{2}$ introduction and the rate of reoxygenation by filtration and surface diffusion. We achieve our target DO by introducing $\mathrm{N}_{2}$ at a flow rate of $\sim 1 \mathrm{l} / \mathrm{min}$ into a 38 -liter aquarium, the surface of which is $75 \%$ covered by plastic "bubble wrap." The oxygen concentration is monitored using a hand-held dissolved oxygen meter. Under these conditions, the target DO is achieved within $2 \mathrm{~h}$ of gassing the aquaria, after which it is maintained for another 18-22 $\mathrm{h}$ [although exposures as short as $2 \mathrm{~h}$ result in measurable lactate accumulation (20)]. After hypoxic fish are sampled, aquaria are aerated with a standard aquarium air pump during the recovery period.

The flow rate of $\mathrm{N}_{2}$ gas can be measured inexpensively by collecting the gas into an inverted, water-filled graduated cylinder whose opening is held under the surface of the water in an aquarium. The rate at which $\mathrm{N}_{2}$ displaces the water from the cylinder is the flow rate. More accurate control of the flow rate is possible if a gas flowmeter with a range of $0-11 / \mathrm{min}$ is available. If two flowmeters are available, as well as compressed air and an appropriate regulator, fine control of DO can be achieved by simultaneously introducing $\mathrm{N}_{2}$ and air at known flow rates (e.g., $0.9 \mathrm{l} / \mathrm{min} \mathrm{N}_{2}$ and $0.1 \mathrm{l} / \mathrm{min}$ air); in this case, the surface of the aquarium may be completely covered by bubble wrap.

\section{Tissue Sampling and Analytical Procedures}

The methods used in this experiment were modified from a previously described protocol (20) to make them suitable for a teaching laboratory exercise. This experiment involves two steps that are conveniently done in two class periods of $3 \mathrm{~h}$ each.

Step 1: sample collection (first class period). Each student group is provided with four microcentrifuge tubes, each containing $200 \mu \mathrm{l}$ of $6 \%$ perchloric acid (PCA) kept on ice. Students label them (1 tube/treatment) and weigh each one to the nearest $0.1 \mathrm{mg}$ with an 
analytical balance. Students must be reminded to wipe moisture off the tubes before weighing and to place them on ice after weighing.

Before fish are sampled, students are instructed on proper sampling techniques and cautioned to minimize handling of the fish during sampling to avoid inducing additional lactate production that could confound the results. Fish are sampled immediately after exposure or after $1 \mathrm{~h}$ or $3 \mathrm{~h}$ of recovery; control fish can be sampled at any convenient time. A student from each group removes a fish from one of the treatment aquaria and places it in a buffered anesthetic $(1 \mathrm{~g}$ MS-222 and $4 \mathrm{~g} \mathrm{NaHCO}_{3}$ per 1 liter of water). After the fish loses equilibrium, it is quickly blotted with paper towels, and the tail is severed at the caudal peduncle with a razor blade. Blood flows under its own pressure from the caudal artery into a heparinized microcapillary tube. With students working as quickly as possible, the whole blood sample is extruded into a microcentrifuge tube containing PCA that has been previously labeled and weighed (see above). The tube is immediately mixed and kept on ice. The fish is euthanized by decapitation, and the carcass is weighed at a convenient time on a top-loading balance. The sampling protocol is repeated for each treatment, resulting in four samples being collected by each student group.

Once all four blood samples are collected, each microcentrifuge tube is reweighed on the analytical balance. Students then calculate the volume of blood added to each tube (in $\mu \mathrm{l}$ ) as the difference between the tube weights before and after sampling (in $\mathrm{mg}$ ) and accounting for a blood density of $1.1 \mathrm{mg} / \mu \mathrm{l}(20)$.

To remove precipitated blood proteins, samples are centrifuged for $10 \mathrm{~min}$ at $15,000 \mathrm{~g}$ (or maximum speed on a microcentrifuge). For each sample, exactly $150 \mu \mathrm{l}$ of the supernatant is transferred into a new, labeled microcentrifuge tube and kept on ice. Students now have supernatants in which reactions that could change the concentration of lactate have been slowed (if not halted) by denaturing metabolic enzymes [lactate dehydrogenase (LDH)] and by keeping the samples cold.

Before lactate is measured, which is done by an enzymatic procedure in a subsequent laboratory period, the acidic supernatants must be neutralized. To each tube, students add $2 \mu$ of methyl orange $[0.05 \%(\mathrm{wt} / \mathrm{vol})]$ and $40 \mu \mathrm{l}$ of a $\mathrm{KOH}$ solution $(2 \mathrm{M} \mathrm{KOH}$ with $0.4 \mathrm{M}$ imidazole). The $\mathrm{KOH}$ solution is then added in 5- $\mu$ l increments until the color changes from pink to yellow, and the total volume of $\mathrm{KOH}$ solution added is noted. Sample neutralization results in the formation of potassium perchlorate salts, which are removed by centrifugation $(10 \mathrm{~min}$ at $15,000 \mathrm{~g})$. At this point, all tubes are frozen $\left(-20^{\circ} \mathrm{C}\right)$ until the later analysis.

Before leaving the first laboratory period, students are asked to calculate the dilution factor (DF) for each blood sample. This DF is calculated from the volume of the blood sample (B), the volume of PCA that was used to denature blood proteins $(200 \mu \mathrm{l})$, the volume of the supernatant $(\mathrm{S} ; 150 \mu \mathrm{l})$, the total volume of $\mathrm{KOH}$ solution used to neutralize the supernatant $(40 \mu \mathrm{l}$ plus what was added in $5-\mu \mathrm{l}$ increments), and the volume of indicating solution (I;2 $2 \mu \mathrm{l})$, as follows:

$$
\begin{aligned}
\mathrm{DF}=\frac{(\mathrm{PCA}+\mathrm{B})}{\mathrm{B}} \times \frac{(\mathrm{S}+\mathrm{I}+\mathrm{KOH})}{\mathrm{S}} & =\frac{(200 \mu \mathrm{l}+\mathrm{B})}{\mathrm{B}} \\
\times & \frac{(150 \mu 1+2 \mu 1+\mathrm{KOH})}{150 \mu \mathrm{l}}
\end{aligned}
$$

EXAMPLE CALCULATION. For a blood sample of $40 \mu$, which required $60 \mu \mathrm{l}$ of $\mathrm{KOH}$ to neutralize, the DF would be the following:

$$
\begin{aligned}
\mathrm{DF}= & \frac{(200 \mu \mathrm{l}+\mathrm{B})}{\mathrm{B}} \times \frac{(150 \mu \mathrm{l}+2 \mu \mathrm{l}+\mathrm{KOH})}{150} \\
= & \frac{(200 \mu 1+40 \mu \mathrm{l})}{40 \mu \mathrm{l}} \times \frac{(150 \mu 1+2 \mu 1+60 \mu \mathrm{l})}{150 \mu \mathrm{l}}=8.48
\end{aligned}
$$

In other words, the blood sample has been diluted 8.48 times for this example. This DF will be used in the final calculations of blood lactate concentrations (see below).

Step 2: enzymatic analysis (second class period). Samples are thawed and kept on ice. Occasionally, further potassium perchlorate precipitation occurs during freezing and thawing, and, in some cases, the $\mathrm{pH}$ of thawed samples will be lower than before freezing. If the indicator has turned pink, then $\mathrm{KOH}$ solution must be added until the indicator turns yellow (5 or $10 \mu \mathrm{l}$ more $\mathrm{KOH}$ solution), and the DFs must be recalculated. Each tube is centrifuged again (10 $\mathrm{min}$ at 15,000 $g$ ) to remove potassium perchlorate salts.

Lactate is measured with a spectophotometric enzymatic assay modified from Noll (16). Students prepare five microcentrifuge tubes containing $200 \mu \mathrm{l}$ of $0,0.05,0.10,0.15$, and $0.20 \mathrm{mg} / \mathrm{ml}$ lactate, using appropriate volumes of a $0.20 \mathrm{mg} / \mathrm{ml}$ lactate stock solution and water. Students calculate their own dilutions, which are verified by the instructor before proceeding.

Students prepare an additional set of 18 microcentrifuge tubes (9 duplicates): 10 tubes ( 5 duplicates) for the standard solution prepared above and 8 tubes ( 4 duplicates) for the blood samples. The tubes are kept at room temperature. To each tube, the following solutions (see the APPENDIX) are added, in order:

- $500 \mu \mathrm{l}$ of water

- $200 \mu \mathrm{l}$ of glutamate buffer solution

- $200 \mu$ l of NAD solution

- $50 \mu \mathrm{l}$ of enzyme solution

Once all four solutions are dispensed in each tube, students put $50 \mu \mathrm{l}$ of the appropriate standard or sample into the corresponding tube, bringing the final volume of all tubes to exactly $1 \mathrm{ml}$. Students must be reminded to pipette only one solution (i.e., one standard or one sample) into each tube.

Tubes are mixed by vortex and incubated $30 \mathrm{~min}$ at $37^{\circ} \mathrm{C}$. After incubation, the absorbance of all tubes is measured in a 1-ml cuvette at $340 \mathrm{~nm}$, using deionized water as a blank. The same cuvette is used for all samples, and it is rinsed with deionized water between all samples.

Students calculate a standard curve of lactate concentration as a function absorbance. This standard curve (typical example shown in Fig. 1) is used to calculate the lactate concentration of the samples. These values correspond to the lactate concentration in the diluted neutralized samples; the lactate concentration of the original blood samples is calculated by multiplying the uncorrected lactate concentrations by the DF previously calculated for each blood sample.

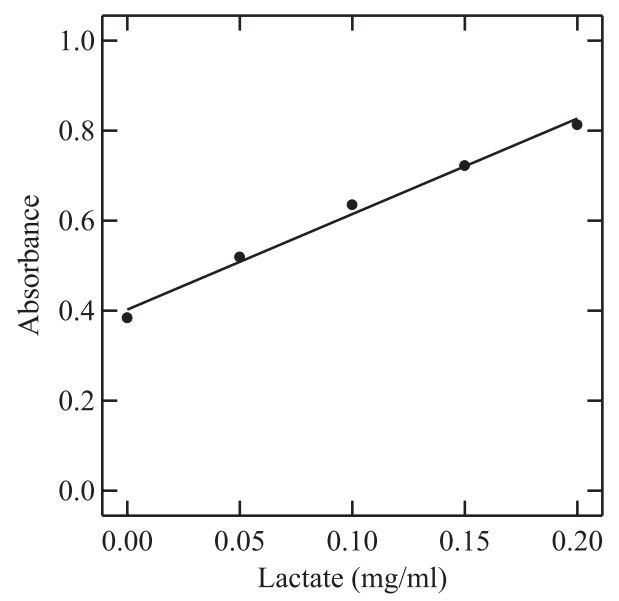

Fig. 1. Typical standard curve of absorbance at $340 \mathrm{~nm}$ as a function of lactate concentration $\left(R^{2}=0.99, P<0.01\right)$. 


\section{Data Analyses}

By combining data from both laboratory sections, the class typically generates a sample size of 48 fish, with 12 fish from each treatment. Differences in blood lactate concentration between treatments are evaluated using ANOVA followed by multiple-comparison tests; we use the Bonferroni procedure because of its robustness (3) and its availability in most statistical software. The effect of body mass on blood lactate may be evaluated by regression analysis, and, if significant, the data are analyzed using analysis of covariance; this is rarely necessary if the fish used have a small range of body sizes. Lactate concentrations may be log transformed if necessary to satisfy assumptions of parametric statistics.

\section{TYPICAL RESULTS AND INTERPRETATIONS}

Control blood lactate is typically $<1 \mathrm{mg} / \mathrm{ml}$, with variation within and between individual laboratory sections due to differences in handling and sampling of fish. Fish subjected to either $5 \mathrm{~min}$ of exercise or 18-22 h of hypoxia both showed elevated blood lactate compared with their respective controls (Fig. 2). The amplitude of the increase is generally between two- and threefold and is typically highly significant. Under the conditions described above, we measured somewhat higher blood lactate after hypoxia exposure; however, we also ob-
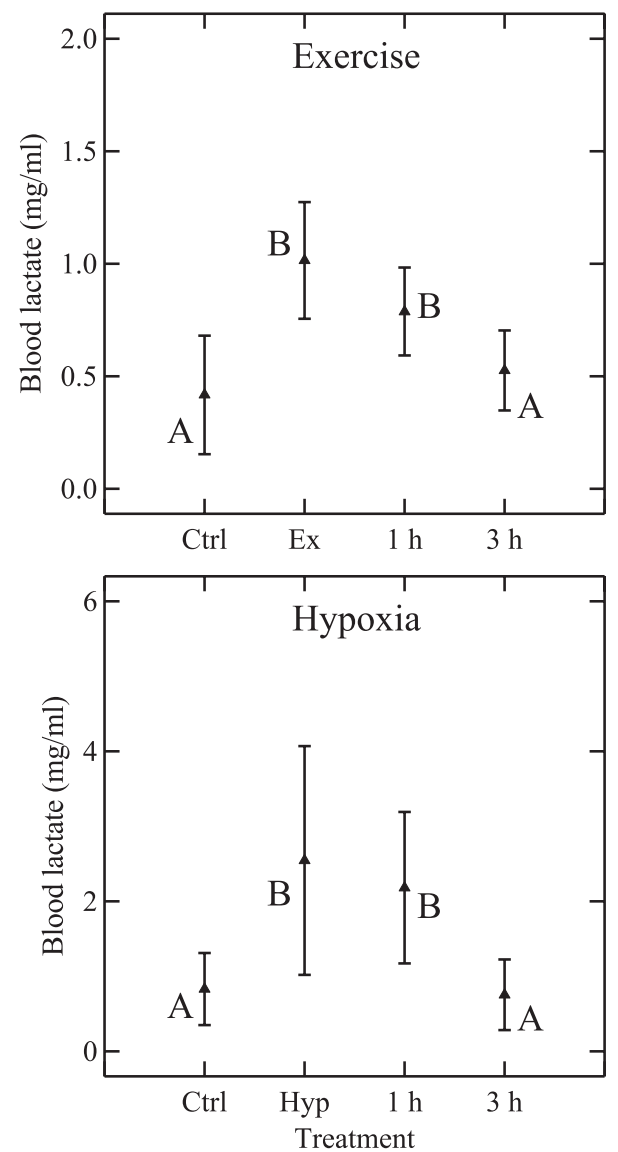

Fig. 2. Blood lactate concentration of Gulf killifish (Fundulus grandis) exposed to different exercise (top; $n=11$ fish/treatment) or hypoxia (bottom; $n=12$ fish/treatment) treatments. Ctrl, control; Ex, exercise; Hyp, hypoxia; $1 \mathrm{~h}, 1 \mathrm{~h}$ of recovery; $3 \mathrm{~h}, 3 \mathrm{~h}$ of recovery. Values are means $\pm \mathrm{SD}$. ${ }_{\mathrm{A}, \mathrm{B}}$ Values with different letters differed significantly $(P<0.05$ by ANOVA followed by a Bonferroni multiple-comparison test). Note that the scale of the $y$-axes differs between the top and bottom graphs. served greater variation in blood lactate of hypoxia-exposed fish probably due to section-to-section differences in the final DO of the exposure. Fish subjected to both treatments displayed a recovery in blood lactate levels over the $3 \mathrm{~h}$ after the exposure protocol. This recovery took between 1 and $3 \mathrm{~h}$, as indicated by the fact that lactate levels at $1 \mathrm{~h}$ of recovery were not significantly different from those measured immediately after the exposure, but, by $3 \mathrm{~h}$, blood lactate was significantly lower than immediately after exposure and was not significantly different from control values.

The results of this exercise dramatically demonstrate that anaerobic metabolism is recruited to augment aerobic energy production during intense exercise or exposure to environmental hypoxia. Students generally are well aware that both conditions can induce anaerobic metabolism. However, they often do not fully understand that, for both conditions, anaerobic metabolism is recruited for the same proximate reason, namely, that the rate of ATP use exceeds what can be produced aerobically, because the rate of oxygen delivery is too low (hypoxia) or because the rate of ATP use is too high (intense exercise). Furthermore, students often are not aware that many animals, including many vertebrates, can tolerate hypoxia for extended periods of time or that aquatic hypoxia is an environmental condition that is common and increasing in prevalence (5). Reenforcing these concepts, using the results of this laboratory, allows instructors to explain the various physiological and behavioral strategies that can be used by animals to minimize the use of anaerobic metabolism by increasing oxygen delivery or reducing ATP use and to explain the potential impact of human activities on the prevalence of hypoxia in aquatic habitats.

The results also demonstrate the phenomenon of "lactate clearance," i.e., when blood lactate eventually returns to control levels after the exercise or hypoxia exposure is ended. These results provide a starting point for discussing the biochemistry of lactate production, oxidation, and gluconeogenesis, including the role of the "Cori cycle." The time needed for complete recovery should be related to the magnitude of the lactate increase, and recovery time is generally longer in ectotherms than endotherms because of large difference in metabolic rates (18).

\section{Common Mistakes Made by Students}

This laboratory experiment involves many steps, using many different solutions in a large number of tubes, leading to a high probably of mistakes. The number of calculations and units used throughout the experiment can also overwhelm students. We provide students with a step-by-step, simplified protocol that includes worksheets for calculations and clearly label all solutions with color-coded tape.

The most common technical mistakes that we observed are related to basic laboratory skills, especially the improper use of pipettors and errors in the calculation of dilutions. We review basic laboratory procedures during the prelaboratory introduction and verify the students' dilution calculations before they proceed in preparing their standard solutions.

When dispensing reagents in the 18 microcentrifuge tubes in preparation for the enzymatic assay, students often lose track of their progress, thus skipping tubes or dispensing a reagent twice in the same tube. We instruct the student to keep track of 
their progress by placing a finger on top of the last tube in which a reagent was dispensed.

Results are also highly sensitive to disturbing the fish during sampling: we suspect that the high variability we sometimes observe in results occurs when we do not emphasize to the students the need to minimize disturbances to the fish during sampling.

\section{Additional Measurements}

The procedures described above can easily be adapted or augmented to demonstrate additional physiological concepts related to exercise or hypoxia tolerance. Below, we offer some additional measurements that can be added to this exercise, and, where available, we provide data from pilot student trials (Table 1).

Hematocrit. The increase in hematocrit is a hallmark feature of the hypoxic response in many vertebrates. In fish, hematocrit also responds to adrenergic stress resulting from either excessive handling or exhaustive exercise (7). If a hematocrit centrifuge is available, it is relatively straightforward to measure hematocrit on the blood samples taken in this experiment.

We have incorporated hematocrit measurements in pilot studies with two laboratory sections using the hypoxia exposure protocol. Although data from each laboratory section were somewhat variable, the combined data showed a clear and statistically significant $(P<0.001$ by $t$-test $)$ increase in hematocrit in $F$. grandis held under hypoxia (Table 1). We have not measured hematocrit during recovery from hypoxia or as part of the exercise protocol.

When hematocrit is measured, then plasma lactate can be measured by breaking the capillary tube at the interface of the packed blood cells and plasma and ejecting only the plasma into the preweighed microcentrifuge tubes containing PCA. If plasma lactate is measured, it is helpful to reduce the volume of PCA used to acidify the sample to $100 \mu \mathrm{l} /$ tube. After the initial centrifugation, only $100 \mu$ l of supernatant is removed and neutralized with correspondingly lower volumes of $\mathrm{KOH}$. These changes in volumes must be incorporated into the calculation of sample DFs. In addition, the density of plasma may be assumed as $1.0 \mathrm{mg} / \mu \mathrm{l}$ (rather than $1.1 \mathrm{mg} / \mu \mathrm{l}$ for whole blood).

Ventilation rate. Another response to low ambient oxygen is an increase in the ventilation rate. It is possible to measure the ventilation rate by the movement of the operculum (gill cover) in fish. These movements are obvious in fish exposed to hypoxia, but are more difficult to see in control fish. In a pilot

Table 1. Additional measures of physiological responses to hypoxia by fish in a student laboratory exercise

\begin{tabular}{ccc}
\hline \multicolumn{1}{c}{ Parameter } & Normoxia & Hypoxia \\
\hline $\begin{array}{l}\text { Hematocrit, } \% \\
n\end{array}$ & $27 \pm 5$ & $36 \pm 7$ \\
$\begin{array}{l}\text { Ventilation rate, breaths/min } \\
n\end{array}$ & $32 \pm 7$ & 12 \\
$\begin{array}{l}\text { Aquatic surface respiration, } \\
\text { proportion of measurements } \\
n\end{array}$ & 12 & $125 \pm 32$ \\
\hline
\end{tabular}

Values are means $\pm \mathrm{SD} ; n$, sample size. Fundulus grandis were held between 0.5 and $1.5 \mathrm{ml} / \mathrm{l}$ oxygen for $18-22 \mathrm{~h}$, and determinations were made according to the text. study with one laboratory section, groups of students were told to focus on one fish in the control or hypoxic aquaria and to count opercular movements over $15 \mathrm{~s}$. The value was multiplied by 4 to get ventilations per minute. Two students from each of six groups counted these movements, yielding 12 measurements in normoxia and hypoxia. Because students did not distinguish among fish, a particular individual might have been observed multiple times and the measurements were not necessarily independent. Hence, we did not apply statistical tests to evaluate the difference between normoxia and hypoxia. Nevertheless, the effect of hypoxia on the ventilation rate was clear, being nearly fourfold higher than in normoxic fish (Table 1). We have not measured the ventilation rate during recovery from hypoxia or as part of the exercise protocol.

Aquatic surface respiration. During hypoxia, many fish, including $F$. grandis, engage in aquatic surface respiration (ASR), in which the fish maintains position near the surface of the water column and ventilates their gills with the welloxygenated water at the air-water interface (12). This behavior is easily observed in undisturbed fish during exposure to hypoxia, and it is rarely observed during normoxia. In a pilot study with one laboratory section, groups of students were told to count the number of fish engaging in ASR during a discrete interval $(10 \mathrm{~s})$. These measurements were repeated by one student from each group for the control and hypoxia treatments. The six values were expressed as a proportion of the number of fish in the aquarium and averaged. The results showed approximately a fourfold increase in the proportion of fish engaging in ASR during hypoxia (Table 1). Had the hypoxia treatment been more severe, the proportion of fish engaging in ASR would have approached 1.0 (13). As with the ventilation measurements, the data were collected by different students on the same fish and could not be considered as six independent measurements. Even though the measurements were not independent, we took the opportunity to introduce students to the $\chi^{2}$-test for evaluating differences in proportions. We have not measured ASR during recovery from hypoxia or as part of the exercise protocol.

Tissue metabolite concentrations. Changes in blood lactate concentration during exercise, hypoxia, or recovery should be coupled with changes in tissue lactate concentration as well as by opposite changes in tissue glycogen content (14). Although conceptually appealing, including these measurements in a student laboratory poses significant logistical problems. Chief among these is the absolute requirement for rapid freezing (freeze clamping) of tissues to stop metabolism. Another difficulty is tissue disruption, which is typically done using mortar and pestle held under liquid $\mathrm{N}_{2}$ before the extraction of the tissues in PCA. We have prepared skeletal muscle samples for tissue lactate measurement as a demonstration in one laboratory section. Because of safety concerns, the instructor handled the liquid $\mathrm{N}_{2}$, freeze clamps, and mortar and pestle. After PCA extraction, we followed the protocol for sample neutralization and analysis described above. Because single samples of normoxic and hypoxic fish were prepared, no conclusions regarding tissue lactate concentrations were drawn, but the students were exposed to approaches needed for tissue metabolite analyses. Although other methods of tissue preparation have been described (9), the procedures involved (tissue digestion in a hot $\mathrm{KOH}$ solution followed by boiling in $95 \%$ ethanol) also involve significant safety concerns. 


\section{APPENDIX}

The following are the solutions needed for tissue preparation and lactate assays. Unless otherwise specified, reagents were ACS grade or better and were purchased from either Sigma Chemical or Roche Applied Science. Amounts are given for two laboratory sections of six groups of students.

PCA solution (6\%). This solution is used to acidify blood samples and is prepared by adding $1.0 \mathrm{ml}$ of concentrated PCA (70-72\%) to $11 \mathrm{ml}$ of deionized water. Aliquots of exactly $200 \mu \mathrm{l}$ are then pipetted into disposable microcentrifuge tubes. Each group of students requires four tubes ( 1 tube for each blood sample).

$\mathrm{KOH}$-imidazole solution $(2 \mathrm{M} / 0.4 \mathrm{M})$. This solution is used to neutralize blood samples. Imidazole (base) is included to prevent overtitration of the samples. This solution is made by dissolving 0.673 $\mathrm{g} \mathrm{KOH}(\mathrm{FW}=56.11)$ and $0.163 \mathrm{~g}$ of imidazole $(\mathrm{FW}=68.08)$ in a final volume of $6.0 \mathrm{ml}$ of deionized water. Each group needs $0.5 \mathrm{ml}$.

Ammonium sulfate solution $(3.2 \mathrm{M}$ ). This solution is used to dilute enzyme solutions and is prepared by dissolving $2.125 \mathrm{~g}$ of ammonium sulfate $(\mathrm{FW}=132.14)$ in a total of $5 \mathrm{ml}$ of deionized water.

Enzyme solution of glutamate-pyruvate transaminase $(78 \mathrm{U} / \mathrm{ml})$ and $\mathrm{LDH}(204 \mathrm{U} / \mathrm{ml})$. This solution is prepared by mixing $700 \mu \mathrm{l}(840$ units) of glutamate-pyruvate transaminase (Roche no. 10105589001) and $500 \mu \mathrm{l}$ (2,200 units) of LDH (Roche no. 10127230001) with 10.8 $\mathrm{ml}$ of $3.2 \mathrm{M}$ ammonium sulfate for a total volume of $12 \mathrm{ml}$. This solution must be refrigerated or kept on ice. Each group receives $1 \mathrm{ml}$.

Glutamate buffer solution $(0.5 \mathrm{M})$. This solution is used for enzymatic assays for the determination of lactate concentration and is prepared by dissolving $4.46 \mathrm{~g} l-(+)$-glutamic acid (Sigma no. G2834, $\mathrm{FW}=147.3)$ in $34 \mathrm{ml}$ of $\mathrm{NaOH}(1 \mathrm{~N})$ and completing to $60 \mathrm{ml}$ with deionized water. The final $\mathrm{pH}$ of the solution is 8.8. Each group receives $5 \mathrm{ml}$.

NAD solution $(25 \mathrm{mM})$. This solution is used for enzymatic assays for the determination of lactate concentration and is prepared by dissolving 0.82 g NAD (Sigma no. N7004; FW = 666.43) in a total of $50 \mathrm{ml}$ of deionized water. This solution must be refrigerated or kept on ice. Each group receives $4 \mathrm{ml}$.

Lactate standard $(0.20 \mathrm{mg} / \mathrm{ml})$. This is the standard for the lactate assay and is prepared by dissolving $0.012 \mathrm{~g} l-(+)$-lactate (Sigma no. L6402) in $60 \mathrm{ml}$ of deionized water. This is more than what is needed for the laboaroty exercise but allows for accurate weighing. Each group received $1 \mathrm{ml}$, and the remainder can be stored in $1-\mathrm{ml}$ aliquots at $-20^{\circ} \mathrm{C}$

\section{ACKNOWLEDGMENTS}

We thank all the Vertebrate Physiology students of the University of New Orleans who participated in this laboratory exercise.

\section{REFERENCES}

1. Boily P, Rees BB, Williamson LAC. Vertebrate osmoregulation: a student laboratory exercise using teleost fish. Adv Physiol Educ 31: 352-357, 2007.

2. Cochran RE, Burnett LE. Respiratory responses of the salt marsh animals, Fundulus heteroclitus, Leiostomus xanthurus, and Palaemonetes pugio to environmental hypoxia and hypercapnia and to the organophos- phate pesticide, azinphosmethyl. J Exp Marine Biol Ecol 195: 122-144, 1996.

3. Curran-Everett D. Multiple comparisons: philosophies and illustrations. Am J Physiol Reg Integr Comp Physiol 279: R1-R8, 2000.

4. Dehn PF, Breed DR. Exercise physiology: muscle metabolism before, immediately following, and during recovery from activity. In: Laboratory Manual for Physiology, edited by Silverthorn DU, Johnson BR, Mills AC. San Francisco, CA: Cummings, 2005, p. 147-162.

5. Diaz RJ. Overview of hypoxia around the world. J Environ Qual 30: 275-281, 2002.

6. Esbaugh AJ, Perry SF, Gilmour KM. Hypoxia-inducible carbonic anhydrase IX expression is insufficient to alleviate intracellular metabolic acidosis in the muscle of zebrafish, Danio rerio. Am J Physiol Regul Integr Comp Physiol 296: R150-R60, 2009.

7. Gallaugher P, Farrell AP. Hematocrit and blood oxygen-carrying capacity. In: Fish Respiration, edited by Perry SF, Tufts BL. San Diego, CA: Academic, 1998, p. 185-227.

8. Hochachka PW, Somero GN. Biochemical Adaptation: Mechanism and Process in Physiological Evolution. New York, NY: Oxford Univ. Press, 2002.

9. Ianuzzo CD, Arbour F, Jamnik V. A laboratory experiment on muscular metabolism and fatigue using the isolated frog muscle preparation. $J$ Biol Educ 21:46-50, 1987.

10. Institute for Laboratory Animal Research, National Research Council. Guide for the Care and Use of Laboratory Animals. Washington, DC: National Academies, 1996.

11. Kerlan JT, Ryan JM, Meagher MA. Blood lactic acid levels after maximal exercise. In: Laboratory Manual for Physiology, edited by Silverthorn DU, Johnson BR, Mills AC. San Francisco, CA: Cummings, 2005, p. 479-490.

12. Kramer DL, McClure M. Aquatic surface respiration, a widespread adaptation to hypoxia in tropical freshwater fishes. Environ Biol Fishes 7: 47-55, 1982.

13. Love JW, Rees BB. Seasonal differences in hypoxia tolerance in gulf killifish, Fundulus grandis (Fundulidae). Environ Biol Fishes 63: 103115, 2002.

14. Mandic M, Lau GY, Nijjar MM, Richards JG. Metabolic recovery in goldfish: a comparison of recovery from severe hypoxia exposure and exhaustive exercise. Comp Biochem Physiol C 148: 332-338, 2008.

15. McArdle WD, Katch FI, Katch VL. Exercise Physiology: Energy, Nutrition, and Human Performance (2nd ed.). Philadelphia, PA: Lea \& Febiger, 1986.

16. Noll FL. (+)-Lactate. In: Methods of Enzymatic Analysis, edited by Bergmeyer HU, Grabl M. Weinheim, Germany: Verlag Chemie, 1985, vol. 6, p. 582-588.

17. Ramsbottom R, Kinch RFT, Morris MG, Dennis AM. Practical application of fundamental concepts in exercise physiology. Adv Physiol Educ 31: 347-351, 2007.

18. Schulte PM, Moyes CD, Hochachka PW. Integrating metabolic pathways in post-exercise recovery of white muscle. J Exp Biol 166: 181-195, 1992.

19. Shoubridge EA, Hochachka PW. Ethanol: novel end product of vertebrate anaerobic metabolism. Science 209: 308-309, 1980.

20. Virani N, Rees BB. Oxygen consumption, blood lactate and interindividual variation in the gulf killifish, Fundulus grandis, during hypoxia and recovery. Comp Biochem Physiol A 126: 397-405, 2000.

21. Wood CM. Acid-base and ion balance, metabolism, and their interactions, after exhaustive exercise in fish. J Exp Biol 160: 285-308, 1991.

22. Wood CM, Turner JD, Graham MS. Why do fish die after severe exercise? J Fish Biol 22: 189-201, 1983. 